\title{
Apoptosis in Cultured Human Fetal Membrane Cells Infected with Influenza Virus
}

\author{
Noboru UChide, ${ }^{*}, a$ Kunio Ohyama, ${ }^{a}$ Toshio Bessho, ${ }^{b}$ Bo Yuan, ${ }^{a}$ and Toshio Yamakawa ${ }^{a}$ \\ Department of Biochemistry, School of Pharmacy, Tokyo University of Pharmacy \& Life Science, ${ }^{a}$ 1432-1 Horinouchi, \\ Hachioji, Tokyo 192-0392, Japan and Yoneyama Maternity Hospital, ${ }^{\text {2 }}$ 2-12 Shin-machi, Hachioji, Tokyo 192-0065, Japan. \\ Received July 10, 2001; accepted October 19, 2001
}

\begin{abstract}
We investigated the induction of apoptosis in cultured human fetal membrane cells infected with influenza virus type $A$. We found that influenza virus yield in supernatants of primary cultured chorion and amnion cells prepared from human fetal membranes increased $6 \mathrm{~h}$ after infection. Chromosomal DNA was fragmented into oligonucleosomes at $48 \mathrm{~h}$ after influenza virus infection in chorion cells but not in mock-infected chorion cells, mock-infected amnion cells or influenza virus-infected amnion cells. The DNA fragmentation in influenza virusinfected chorion cells was evident at $24 \mathrm{~h}$ after infection and depended on the multiplicity of infection at $48 \mathrm{~h}$. Incubating influenza virus-infected chorion cells with ribavirin, an inhibitor of viral RNA synthesis, reduced the increase in virus yield and simultaneously blocked DNA fragmentation. These results suggest that both chorion and amnion cells become infected with influenza virus, but that influenza virus infection induces apoptosis in chorion, but not typical apoptosis characterized by DNA ladder formation in amnion cells. We further observed that influenza virus replication is associated with the induction of apoptosis.
\end{abstract}

Key words apoptosis; fetal membrane; influenza virus; cytocidal infection; persistent infection; ribavirin

When a virus encounters a susceptible cell, the virus enters it to initiate cytocidal, persistent, latent or abortive cell infection. The influenza virus induces cytocidal infection accompanied by virus production and cell death in several types of cultures such as HeLa and Madin-Darby canine kidney (MDCK) cell lines and human peripheral blood monocytes in vitro, all of which die through the mechanism of apoptosis. $^{1-4)}$

The human influenza virus usually infects the human respiratory organs. However, influenza virus was isolated from blood, ${ }^{5-8)}$ as well as extrapulmonary regions such as lymph node, spleen, liver, kidney, adrenal glands, meninges, ${ }^{7,9-11)}$ and cerebrospinal fluid. ${ }^{12,13)}$ These findings substantiate the occurrence of viremia in influenza virus infection and the extrapulmonary dissemination of the virus. Furthermore, influenza virus has been isolated from fetal heart, ${ }^{10)}$ placenta ${ }^{14)}$ and amniotic fluid, ${ }^{10,15)}$ suggesting the occurrence of fetal, placental and amniotic fluid infections with this virus.

The influenza virus has not so far been isolated from the fetal membranes of a mother who died of influenza virus infection to our knowledge. However, the virus has been isolated from the placenta and amniotic fluid. ${ }^{14,15)}$ Additionally, organ cultures of human placenta allow influenza virus replication. ${ }^{16)}$ The influenza virus may spread from the placenta to fetal membranes because they are continuous with the placenta. Furthermore, since amniotic fluid fills amniotic cavity formed by fetal membranes, influenza virus in amniotic fluid may influence the membrane cells. However, little is understood about the influence of influenza virus on human fetal membrane cells.

We investigated the relationship between the influenza virus and cultured human fetal membrane cells by studying virus production and the apoptotic death of these cells in vitro. We found that the influenza virus induced cytocidal infection in chorion cells, persistent infection accompanied by virus production and cell survival in amnion cells, and that influenza virus-infected chorion cells became degraded through the apoptotic pathway. The present study demon- strates that the host cells make the choice to commit to degradation through this pathway.

\section{MATERIALS AND METHODS}

Chemicals Ribavirin (1- $\beta$-D-ribofuranosyl-1,2,4-triazole3-carboxamide) was purchased from Sigma (MO, U.S.A.).

Influenza Virus Propagation and Plaque-Forming Assay Influenza virus type A (PR/8/34, H1N1) was propagated in the allantoic cavity of 11-d-old embryonal chicken eggs for 48 to $72 \mathrm{~h}$ at $35^{\circ} \mathrm{C}$ as described. ${ }^{2}$ Plaque-forming capacity was assayed on confluent monolayers of MDCK (NBL-2) cells (Human Science Research Resources Bank, Japan) as described. ${ }^{4}$ The chorioallantoic fluid contained $8 \times 10^{8}$ plaque-forming units (PFU)/ml and the hemagglutination titer using human erythrocytes was $1: 256$.

Cell Cultures and Virus Infection Human fetal membranes were prepared aseptically from placentas obtained by cesarean section in the month of normal parturition. Primary cultured chorion and amnion cells were prepared from the membranes as described. ${ }^{17)}$ After removing the culture supernatant, confluent monolayer cells at a density of $8 \times 10^{4}$ cells $/ \mathrm{cm}^{2}$ were washed with sterile phosphate-buffered saline (PBS). Chorioallantoic fluid containing influenza virus was diluted with a serum-free medium, then $0.04 \mathrm{ml} / \mathrm{cm}^{2}$ was added to the cells and incubated for $1 \mathrm{~h}$ at $37^{\circ} \mathrm{C}$. Inoculation with serum-free medium was referred to as mock-infection. Cells infected with influenza virus or mock-infected cells were washed with PBS and cultured for various periods in culture medium in the absence or presence of ribavirin.

Cell Damage Assay Lactate dehydrogenase (LDH) activity was measured using the LDH-Cytotoxic Test Wako kit (Wako Pure Chemical Industry, Osaka, Japan). Culture medium served as the background control. Mock-infected cells were lysed in culture medium containing $0.2 \%$ Tween 20 , and the cell lysate after centrifugation at $12000 \times \boldsymbol{g}$ for 10 min was used as the non-damaged control. Culture supernatants were collected by centrifugation at $450 \times \boldsymbol{g}$ for $5 \mathrm{~min}$ 

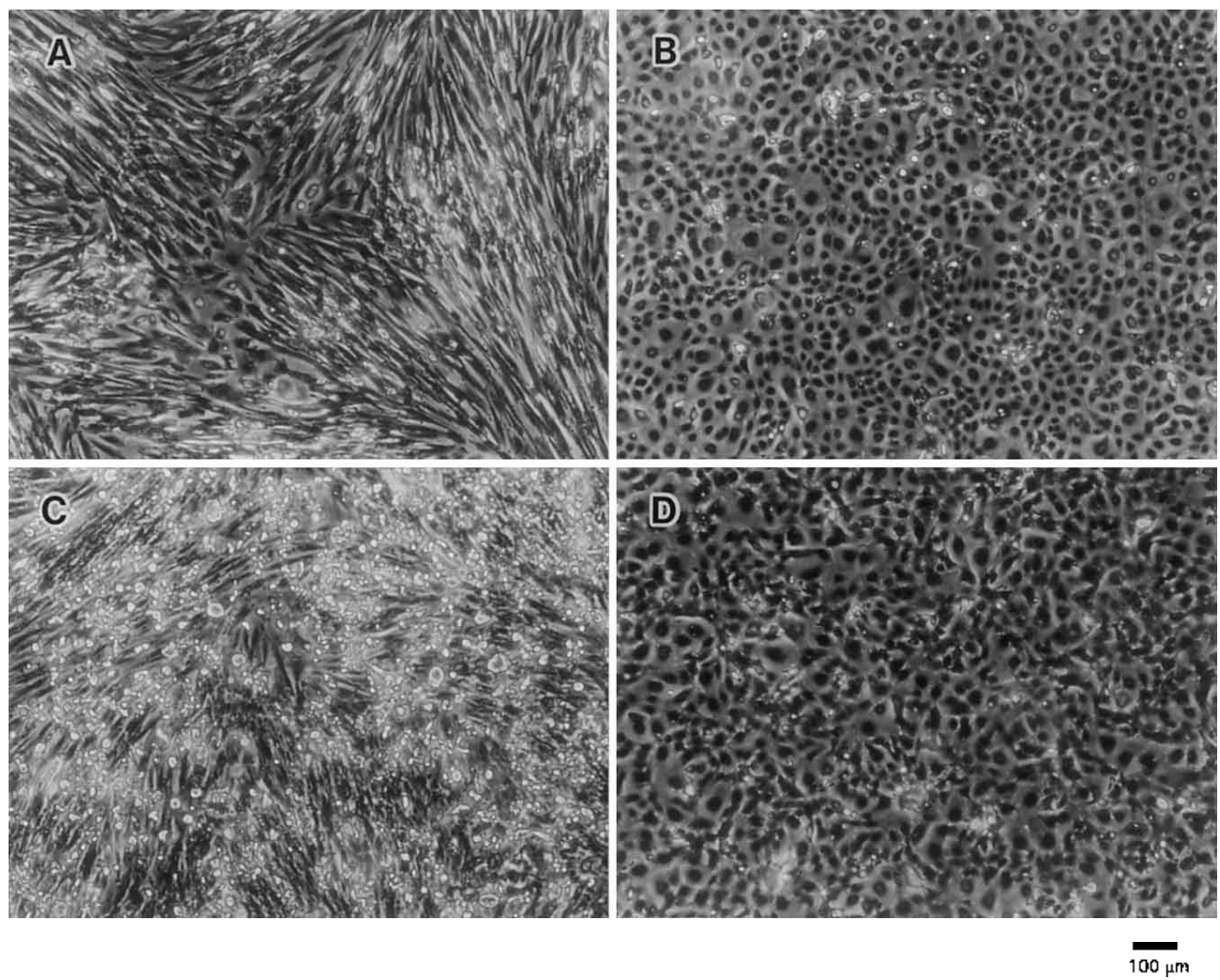

Fig. 1. Cytopathic Effect of Influenza Virus Infection

After influenza virus infection at MOI $=40$, chorion (panels A and C) and amnion (panels B and D) cells were cultured for 0 (panels A and B) and $48 \mathrm{~h}$ (panels C and D). Photomicrographs show phase contrast views of the cells. Many rounded and detached cells are evident among influenza virus-infected chorion cells at $48 \mathrm{~h}$ (panel B).

at $4{ }^{\circ} \mathrm{C}$. Samples were diluted 32 -fold with PBS, then $50 \mu 1$ was added into the wells of a 96 well plate and then mixed with $50 \mu \mathrm{l}$ of "substrate solution" from the kit. The mixture was stirred and incubated at room temperature for $30 \mathrm{~min}$. The reaction was stopped by adding $100 \mu \mathrm{l}$ of "stopping solution" provided with the kit. Absorption at $550 \mathrm{~nm}$ in the reaction mixture was measured using an MTP-32 microplate reader (CORONA ELECTRIC Co., Ibaraki, Japan). Cell damage was calculated as a percentage of LDH leakage from damaged cells using the following function: Cell damage $(\%)=100 \times(\mathrm{CS}-\mathrm{BC}) /(\mathrm{NDC}-\mathrm{BC}) . \mathrm{CS}, \mathrm{BC}$ and $\mathrm{NDC}$ mean absorption of culture supernatant, background control and non-damaged control, respectively.

DNA Fragmentation Assay The DNA fraction was extracted from cells as described. ${ }^{18)}$ Extracted DNA was dissolved in TE buffer [10 mM Tris-HCl, pH 8.0, $1 \mathrm{~mm}$ ethylenediaminetetraacetic acid, disodium salt (EDTA-2Na)], and the DNA concentration was determined by staining with Hoechst 33258 as described. ${ }^{19)}$ Extracted DNA $(10 \mu \mathrm{g})$ and a Ready-Load ${ }^{\mathrm{TM}} 100 \mathrm{bp}$ DNA Ladder (GibcoBRL, MD, U.S.A.) as a DNA size marker were resolved by electrophoresis on $2.0 \%$ agarose gel (Agarose X, Wako Pure Chemical Industry, Japan) using TBE buffer ( $89 \mathrm{~mm}$ Tris, $89 \mathrm{~mm}$ boric acid, $2 \mathrm{~mm}$ EDTA-2Na). The gel was stained with ethidium bromide and viewed on a UV transilluminator. For fragmentation analysis, photographs of the gel were digitized using a scanner (ScanJet 4c, Hewlett Packard) and scanning software (DeskScan II, Ver. 2.3, Hewlett Packard) on a personal computer. The density of the gray level of the digitized portrait as a relative amount of DNA was calculated using NIH Image 1.60. DNA larger than $2072 \mathrm{bp}$ and DNA ranging in size from 100 to $2072 \mathrm{bp}$ were designated as high molecular weight DNA and fragmented DNA, respectively. The fragmentation rate was calculated as the relative amount of fragmented DNA in the digitized photograph.

\section{RESULTS AND DISCUSSION}

Figures $1 \mathrm{~A}$ and $\mathrm{B}$ show primary cultured chorion and amnion cells prepared from human fetal membranes at $0 \mathrm{~h}$ after influenza virus infection at multiplicity of infection (MOI) of 40. Most of the cells prepared from chorion tissue that were spindle-shaped or narrow rectangles and arranged in a particular orientation were designated as chorion cells (Fig. 1A). Most of the cells prepared from amnion tissue that were epithelial-like and arranged in a pavement-like structure were designated as amnion cells (Fig. 1B). The features of the chorion and amnion cell morphology were the same as those described by Masaki. ${ }^{20)}$ Forty-eight hours after influenza virus infection at $\mathrm{MOI}=40$, many chorion cells were rounded and detached (Fig. 1C), but these phenomena were not observed in amnion cells (Fig. 1D). These microscopic observations confirmed a cytopathic effect of influenza virus infection in chorion, but not amnion cells.

We examined whether chorion and amnion cells were infected with influenza virus. Virus yields in culture supernatants of both chorion (Fig. 2A) and amnion cells (Fig. 2B) increased from $6 \mathrm{~h}$ after influenza virus infection with $\mathrm{MOI}=$ 4 , and the increases reached a plateau at $12 \mathrm{~h}$ after infection. Compared with virus yields immediately after the infection, 

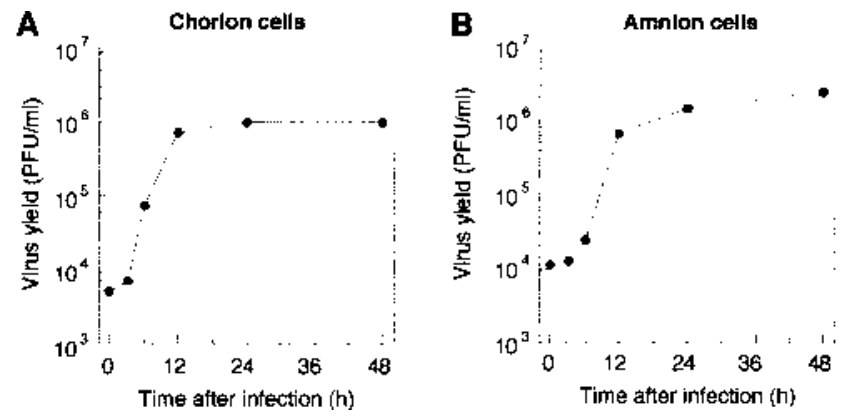

Fig. 2. Influenza Virus Production

After influenza virus infection at $\mathrm{MOI}=4$, chorion (panel A) and amnion (panel B) cells were cultured for various periods, then plaque-forming ability of culture supernatants was assayed. Virus yields in culture supernatant are indicated as plaque-forming units $(\mathrm{PFU}) / \mathrm{ml}$
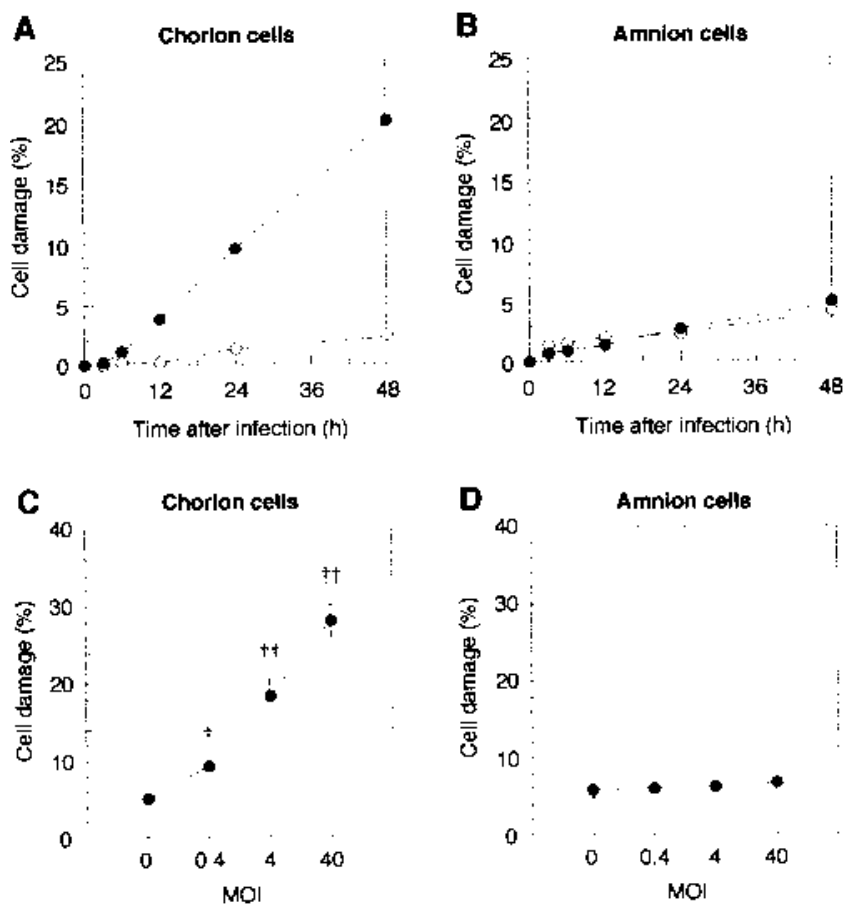

Fig. 3. Cell Damage Induced by Influenza Virus Infection

After mock-infection (opened circular) and influenza virus infection at $\mathrm{MOI}=40$ (closed circular), chorion (panel A) and amnion (panel B) cells were cultured for 0, 3, $6,12,24$ and $48 \mathrm{~h}$. After influenza virus infection $(\mathrm{MOI}=0,0.4,4$ and 40$)$, chorion (panel C) and amnion (panel D) cells were cultured for $48 \mathrm{~h}$. Cell damage was estimated by lactate dehydrogenase (LDH) leakage from damaged cells into culture medium as described in Materials and Methods. Data in panels C and D are shown as means and standard deviation $(n=4)$. Statistical analyses using $t$-test show significant differences between mock- and influenza virus infection in chorion cells and no significant difference in amnion cells.

virus yields in the culture supernatants of both cells increased about 200 -fold at $48 \mathrm{~h}$. These results showed that infectious influenza virus particles were produced and released from both chorion and amnion cells, indicating influenza virus infection.

LDH is widespread in cell membranes and cytoplasm, and it is released into the culture medium when the cells are damaged by influenza virus infection. ${ }^{21)}$ Cell damage of influenza virus-infected chorion and amnion cells was estimated by LDH leakage into the culture medium. After mock-infection and influenza virus infection at $\mathrm{MOI}=40$, chorion and amnion cells were cultured for various periods. Damage to chorion cells infected with the influenza virus gradually increased from 12 to $48 \mathrm{~h}$ and to a higher extent than in mockinfected cells (Fig. 3A). Damage to amnion cells caused by influenza virus infection was increased somewhat but was similar to that of mock-infected amnion cells (Fig. 3B). Forty-eight hours after infection, damage of chorion cells significantly increased in an MOI-dependent manner (Fig. 3C), whereas that of amnion cells did not (Fig. 3D). These data indicated that influenza virus infection induced cell damage in chorion, but not in amnion cells, suggesting that cell damage estimated by LDH leakage was associated with cytopathic effects such as cell rounding and detachment but not with virus production. Accordingly, influenza virus induced cytocidal infection accompanied by virus production and cell degradation in chorion cells and persistent infection accompanied by virus production and cell survival in amnion cells.

Whether or not influenza virus infection induced apoptosis in chorion and amnion cells was examined by DNA fragmentation assay (Fig. 4). Forty-eight hours after mock- and influenza virus infection at $\mathrm{MOI}=40$, influenza virus-infected chorion cell-DNA fragmented into oligonucleosomes (DNA ladder) (Fig. 4A, lane 2) whereas mock-infected chorion cellDNA (Fig. 4A, lane 1), as well as mock- and influenza virusinfected amnion cell-DNAs did not (Fig. 4A, lanes 3 and 4, respectively). The DNA fragmentation rate increased $30 \%$ in chorion cells after influenza virus infection but not in amnion cells (Fig. 4B). A DNA ladder did not appear in mock-infected cell-DNA (Fig. 4C, lane 1) and was scarcely detected at $\mathrm{MOI}=0.4$ (Fig. $4 \mathrm{C}$, lane 2 ) but was clearly revealed with influenza virus-infected cell-DNA at MOI $=4$ and 40 (Fig. $4 \mathrm{C}$, lanes 3 and 4, respectively). The DNA fragmentation rate increased from $\mathrm{MOI}=0.4$ and was dependent on the MOI (Fig. 4D). After influenza virus infection at $\mathrm{MOI}=40$, a DNA ladder was detected at $24 \mathrm{~h}$ (Fig. 4E, lane 3), which became quite distinct at $48 \mathrm{~h}$ (Fig. 4E, lane 4). The DNA fragmentation rate also increased gradually from $24 \mathrm{~h}$ after infection, increasing to over $30 \%$ at $48 \mathrm{~h}$ after infection, depending on the incubation period (Fig. 4F). Because DNA fragmentation is a key feature of apoptotic cell death, ${ }^{22)}$ influenza virus infection appeared to have induced apoptosis in chorion, but not typical apoptosis characterized by DNA ladder formation in amnion cells. Therefore, the degradation of chorion cells infected with influenza virus appeared to arise through the apoptotic pathway.

To determine whether or not influenza virus replication was implicated in the apoptosis of influenza virus-infected chorion cells, we used the antiviral agent ribavirin, which inhibits the replication of single-stranded RNA viruses. ${ }^{23)}$ Ribavirin is a guanosine analogue that reduces influenza virus ribonucleoprotein synthesis through reducing the size of the cellular guanosine $5^{\prime}$-triphosphate pool and by directly affecting viral replicative enzymes. ${ }^{24)}$ Furthermore, Eriksson et $a l$. found that ribavirin triphosphate, a cellular metabolite of ribavirin, selectively inhibits influenza virus RNA-dependent RNA polymerase. ${ }^{25}$ We examined the effect of ribavirin on influenza virus replication in chorion and amnion cells. Virus yields in culture supernatants from both cell types increased about 300 -fold in the absence of ribavirin, but increased only 3- or 4-fold at a concentration of $1 \mathrm{~mm}$ ribavirin (Table 1). We then examined the effect of ribavirin on the DNA frag- 
A

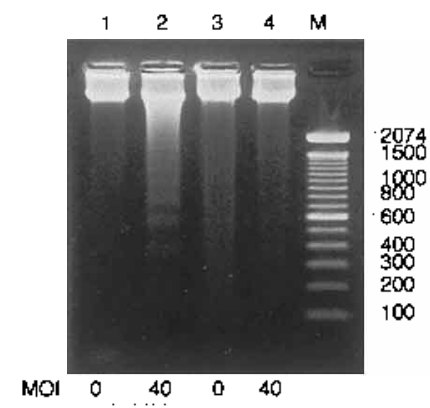

Cells Chorion Amnon

B

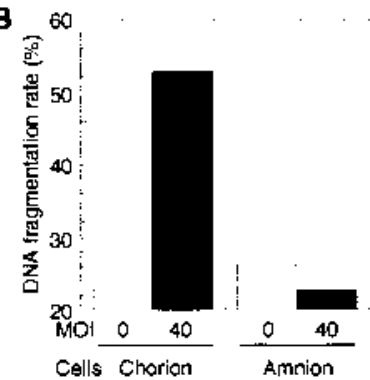

C

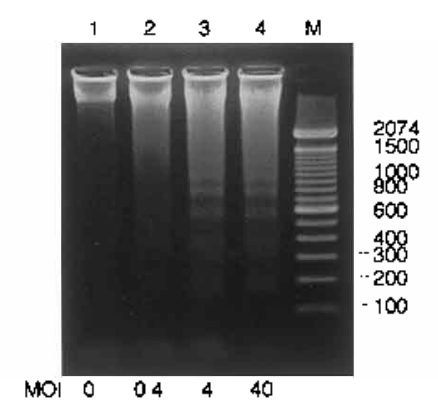

D

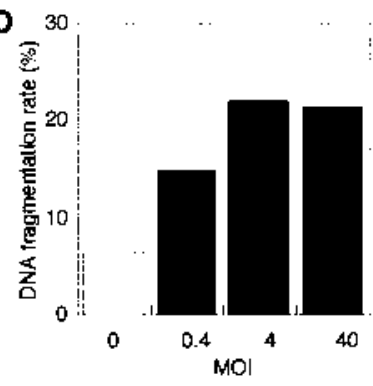

$\mathbf{E}$

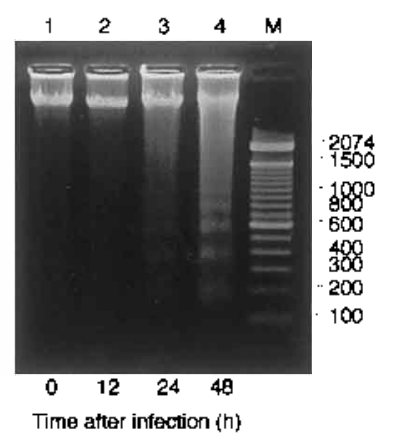

$\mathbf{F}$

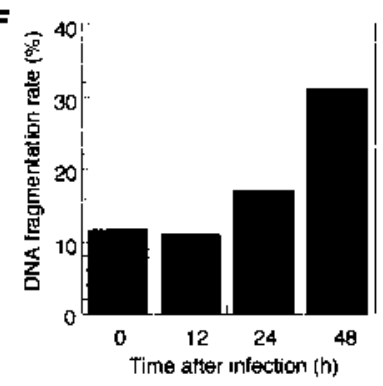

Fig. 4. Oligonucleosomal DNA Fragmentation Induced by Influenza Virus Infection

(Panel A) After mock- (lanes 1 and 3) and influenza virus infection at MOI=40, (lanes 2 and 4), chorion (lanes 1 and 2) and amnion cells (lanes 3 and 4 ) were cultured for 48 h. (Panel C) After mock- (lane 1) and influenza virus infection at MOI=0.4, 4 and 40 (lanes 2, 3 and 4, respectively), chorion cells were cultured for 48 h. (Panel E) After influenza virus infection at $\mathrm{MOI}=40$, chorion cells were cultured for $0,12,24$ and $48 \mathrm{~h}$ (lanes 1 to 4 ). Profiles of agarose gel electrophoresis of DNA fractions extracted from cells are shown in panels A, C and E. Lane M shows DNA size markers. Size of DNA fragments in lane M is shown in terms of base pairs at right of panel. DNA fragmentation rates are calculated from photographs in panels A, C and E as described in Materials and Methods, and results are shown in panels B, D and F, respectively. Open and closed columns indicate DNA fragmentation rates of mock-infected $(\mathrm{MOI}=0)$ cells and influenza virus-infected $(\mathrm{MOI}=0.4,4$ and 40$)$ cells, respectively.

Table 1. Inhibition of Influenza Virus Production with Ribavirin

\begin{tabular}{|c|c|c|c|}
\hline \multirow{2}{*}{$\begin{array}{l}\text { Concentration of } \\
\text { ribavirin }(\mathrm{mm})\end{array}$} & \multirow{2}{*}{$\begin{array}{l}\text { Time after } \\
\text { infection (h) }\end{array}$} & \multicolumn{2}{|c|}{$\begin{array}{l}\text { Virus yield in culture supernatant } \\
\qquad(\mathrm{PFU} / \mathrm{ml})\end{array}$} \\
\hline & & Chorion cells & Amnion cells \\
\hline 0 & 0 & $1280 \pm 162$ & $1420 \pm 318$ \\
\hline 1 & 0 & $1330 \pm 288$ & $1150 \pm 132$ \\
\hline 0 & 24 & $439000 \pm 50100$ & $421000 \pm 3470$ \\
\hline 1 & 24 & $3970 \pm 684^{\dagger}$ & $4260 \pm 443^{\dagger}$ \\
\hline
\end{tabular}

Chorion and amnion cells were cultured for $24 \mathrm{~h}$ before influenza virus infection in the absence or presence of $1 \mathrm{~mm}$ ribavirin. The cells were infected with influenza virus at a multiplicity of infection (MOI) of 4 and cultured in the absence or presence of 1 $\mathrm{mm}$ ribavirin. Culture supernatants were collected at 0 and $24 \mathrm{~h}$ later and plaque-forming ability was assayed. Virus yields in the culture supernatant are indicated as plaqueforming units (PFU)/ml. Data are shown as means and standard deviations. Statistical analyses using a $t$-test $(n=3)$ show significant differences in virus yields at $24 \mathrm{~h}$ after infection between absence and presence of $1 \mathrm{~mm}$ ribavirin $(\dagger p<0.005)$.

mentation resulting from influenza virus infection (Fig. 5). The influenza virus-infected cell-DNA ladder (Fig. 5A, lane 2) was slightly and significantly decreased by $0.1 \mathrm{~mm}$ (Fig. $5 \mathrm{~A}$, lane 4) and by $1 \mathrm{~mm}$ ribavirin (Fig. 5A, lane 5), respectively. Ribavirin at $0.01,0.1$ and $1 \mathrm{~mm}$ inhibited 17,43 and 97\% of DNA fragmentation, respectively (Fig. 5B). Finally, we examined the time-dependence of the inhibitory effect of ribavirin on DNA fragmentation induced by influenza virus infection (Fig. 5C). The influenza virus-infected cell-DNA ladder was considerably decreased when cells were incubated with $1 \mathrm{~mm}$ ribavirin for $24 \mathrm{~h}$ before influenza virus infection plus post-treatment (Fig. 5C, lane 3). A prior incubation with $1 \mathrm{~mm}$ ribavirin for $24,4,2$ and $0 \mathrm{~h}$ plus post-treatment inhibited $75,49,21$ and $13 \%$ of DNA fragmentation, respectively (Fig. 5D). These results demonstrated that ribavirin simulta- neously inhibited influenza virus replication and apoptosis in influenza virus-infected cells. We assume that ribavirin reduces the synthesis of influenza virus ribonucleoprotein rather than the synthesis of the host RNA. This result suggested that ribavirin blocked influenza virus infection-induced apoptosis through the inhibition of influenza virus replication. Therefore, influenza virus replication is thought to be associated with the induction of apoptosis.

In conclusion, influenza virus induces cytocidal and persistent infection in cultured chorion and amnion cells respectively, derived from human fetal membranes. Chorion cells infected with influenza virus became degraded through the apoptotic pathway, and viral replication is associated with this process. A previous study has suggested that influenza virus replication is essential for apoptosis induction because UV-inactivated influenza virus induces little or no apoptosis. ${ }^{1)}$ Although evidence from the present study does not contradict this notion, typical apoptosis characterized by DNA ladder formation was not induced in amnion cells even though influenza virus replicated. Accordingly, the decision to degrade through the apoptotic pathway appeared to be taken by host cell itself. Apoptosis is a tightly regulated process involving several checkpoints before irreversible cellular degradation begins; the process consists of initiation, commitment and degradation phases which are quite distinct. ${ }^{26,27)}$ Since the inhibition of influenza virus replication was not accompanied by apoptosis, influenza virus replication may be associated with the initiation phase of the apoptotic process. Therefore, a commitment to apoptotic cell death is initiated by influenza virus replication in chorion cells but is lost in amnion cells.

Similar phenomena such as permissive virus replication and the absence of a DNA ladder in amnion cells have been 

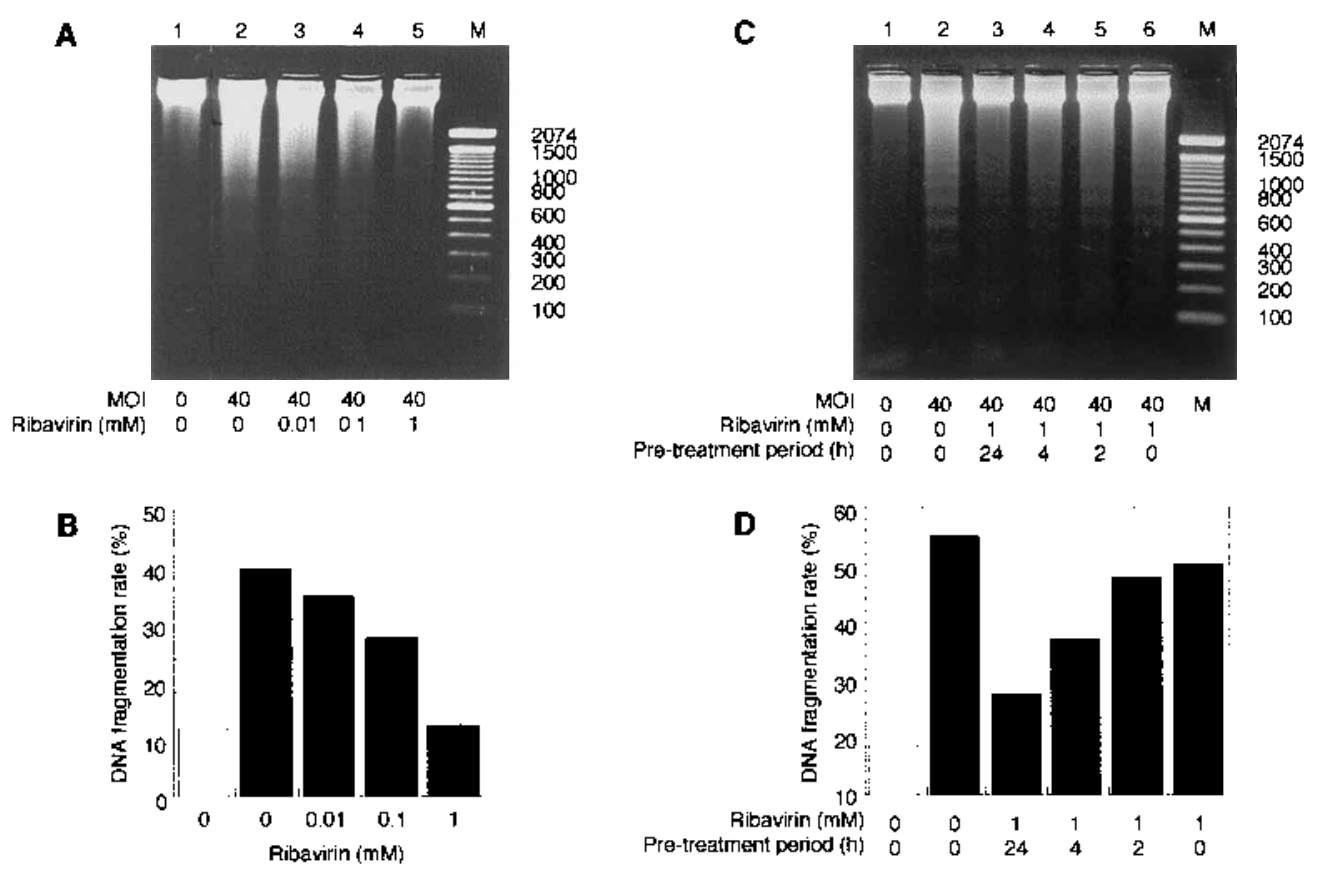

Fig. 5. Inhibition of the DNA Fragmentation Resulting from Influenza Virus Infection with Ribavirin

(Panel A) Chorion cells cultured for $24 \mathrm{~h}$ in absence (lanes 1 and 2) or presence of $0.01,0.1$ and $1 \mathrm{~mm}$ ribavirin (lanes 3, 4 and 5, respectively) before infection. Cells were mockinfected (lane 1) or infected with influenza virus at MOI $=40$ (lanes 2 to 5). Infected cells cultured for $48 \mathrm{~h}$ in absence (lanes 1 and 2 ) or presence of $0.01,0.1$ and $1 \mathrm{~mm}$ ribavirin (lanes 3, 4 and 5, respectively). (Panel C) Chorion cells cultured for 24 (lane 3), 4 (lane 4), 2 (lane 5) and $0 \mathrm{~h}$ (lane 6) before infection in absence (lanes 1 and 2) or presence of $1 \mathrm{~mm}$ ribavirin (lanes 3 to 6 ). Cells mock-infected (lane 1) or infected with influenza virus at MOI=40 (lanes 2 to 6 ) then cultured for $48 \mathrm{~h}$ in absence (lanes 1 and 2) or presence of $1 \mathrm{~mm}$ ribavirin (lanes 3 to 6). Agarose gel electrophoresis of DNA fraction extracted from cells is shown in panels A and C. Lane M in panel shows DNA size markers. Size of DNA fragments in lane $\mathrm{M}$ is shown in terms of base pairs at right of panel. DNA fragmentation rates are calculated from photographs of panels A and $\mathrm{C}$ as described in Materials and Methods, and results are shown in panels B and D, respectively. Open and closed columns indicate DNA fragmentation rate of mock- $(\mathrm{MOI}=0)$ and influenza virus-infected $(\mathrm{MOI}=40)$ cells, respectively.

documented. The formation of a DNA ladder is mediated by caspase-activated deoxyribonuclease (CAD) activity. ${ }^{28)}$ Takizawa et al. have demonstrated that DNA ladder formation in HeLa cells infected with influenza virus is blocked by caspase inhibitors, but these inhibitors did not inhibit virus replication, suggesting that caspase activation is downstream of viral replication. ${ }^{4)} \mathrm{Bcl}-2$ blocks the release of apoptosis-inducing factor (AIF) and cytochrome c, which activates caspases, from mitochondria. ${ }^{29,30)}$ Olsen et al. reported that the expression of bcl-2 in MDCK cells blocks influenza virus-induced DNA ladder formation but not substantial virus replication. ${ }^{31)}$ Accordingly, amnion cells may possess a natural inhibitory mechanism for apoptosis such as the inhibition of caspase activation and a blockade of cytochrome $\mathrm{c}$ and AIF release. Finally, we propose that cell infection may become persistent through an intrinsic inhibitory mechanism for apoptosis in host cells.

\section{REFERENCES}

1) Price G. E., Smith H., Sweet C., J. Gen. Virol., 78, 2821-2829 (1997).

2) Hinshaw V. S., Olsen C. W., Dybdahl-Sissoko N., Evans D., J. Virol., 68, 3667-3673 (1994).

3) Fesq H., Bacher M., Nain M., Gemsa D., Immunobiology, 190, 175182 (1994).

4) Takizawa T., Tatematsu C., Ohashi K., Nakanishi Y., Microbiol. Immunol., 43, 245-252 (1999).

5) Naficy K., New Engl. J. Med., 269, 964 - 966 (1963).

6) Stanley E. D., Jackson G. G., Trans. Assoc. Am. Phisi., 79, 376-387 (1969).

7) Lehmann N. I., Gust I. D., Med. J. Aust., 2, 1166-1169 (1971).

8) Ritova V. V., Schastnyi E. I., Ratushkina L. S., Shuster I. Y., J. Hyg.
Epidemiol. Microbiol. Immunol., 23, 35-41 (1979).

9) Kaji M., Oseasohn R., Jordan W. S., Dingle J. J. H., Proc. Soc. Exp. Biol. Med., 100, 272-275 (1959).

10) Yawn D. H., Pyeatte J. C., Joseph J. M., Eichler S. L., Garcia-Bunuel R., JAMA, 216, 1022-1023 (1971).

11) Roberts G. T., Roberts J. T., Can. Med. Assoc. J., 115, 435-437 (1976).

12) Zhdanov V. M., Ritova V. V., Klin. Med. Mosk., 37, 45-48 (1959).

13) Hakoda S., Nakatani T., Arch. Intern. Med., 160, 1041-1045 (2000).

14) Mel'nikova V. F., Tsinzerling A. V., Aksenov O. A., Vydumkina S. P., Kalinina N. A., Arkh. Patol., 49, 19-25 (1987).

15) McGregor J. A., Burns J. C., Levin M. J., Burlington B., Meiklejohn G., Am. J. Obstet. Gynecol., 149, 856-859 (1984).

16) Rosztóczy I., Sweet C., Toms G. L., Smith H., Br. J. Exp. Path., 56, $322-328$ (1975)

17) Ohyama K., Uchide N., Suzuki R., Iwamoto N., Bessho T., Watanabe H., Hirakawa S., Yamakawa T., Cancer Detec. Prev., 24, 61-71 (2000).

18) Ohyama K., Oka K., Emura A., Tamura H., Suga T., Bessho T., Hirakawa S., Yamakawa T., Biol. Pharm. Bull., 21, 1024-1029 (1998).

19) Cesarone C. F., Bolognesi C., Santi L., Anal. Biochem., 100, 188-197 (1979).

20) Masaki K., Acta Obst. Gynaec. Jpn., 44, 643-649 (1992).

21) Watanabe W., Sudo K., Asawa S., Konno K., Yokota T., Shigeta S., J. Virol. Methods, 51, 182-192 (1995).

22) Wyllie A. H., Kerr J. F. R., Currie A. R., Int. Rev. Cytol., 68, 251-306 (1980).

23) Patterson J. L., Fernandez-Larsson R., Rev. Infect. Dis., 12, 11391146 (1990).

24) Wray S. K., Gilbert B. E., Noall M. W., Knight V., Antiviral Res., 5, 29-37 (1985).

25) Eriksson B., Helgstrand E., Johansson N. G., Larsson A., Misiorny A., Noren J. O., Philipson L., Stenberg K., Stening G., Stridh S., Öberg, B., Antimicrob. Agents Chemother., 11, 946-951 (1977).

26) Kroemer G., Petit P., Zamzami N., Vayssière J.-L., Mignotte B., FASEB J., 9, 1277-1287 (1995).

27) Oltvai Z. N., Korsmeyer S. J., Cell, 79, 189-192 (1994). 
28) Nagata S., Exp. Cell Res., 256, 12-18 (2000).

29) Yang J., Liu X., Bhalla K., Kim C. N., Ibrado A. M., Cai J., Peng T.-I., Jones D. P., Wang X., Science, 275, 1129-1132 (1997).

30) Susin S. A., Zamzami N., Castedo M., Hirsch T., Marchetti P., Macho
A., Daugas E., Geuskens M., Kroemer G., J. Exp. Med., 184, 13311341 (1996).

31) Olsen C. W., Kehren J. C., Dybdahl-Sissoko N. R., Hinshaw V. S., J. Virol., 70, 663-666 (1996). 